\title{
Low External Input Sustainable Agriculture: expectations and realities
}

\author{
J.J. KESSLER AND M. MOOLHUIJZEN \\ Matrix Consultants in Development Management, Korte Jansstraat 7, \\ NL-3512 GM Utrecht, The Netherlands
}

Received 15 December 1993; accepted 7 July 1994

\begin{abstract}
Low External Input Sustainable Agriculture (LEISA) is receiving increased attention, both as a sustainable alternative to Green Revolution-like strategies making intensive use of external inputs, and as a strategy of sustainable agriculture in resource-poor environments where no or very few external inputs are used. The evaluation of LEISA field-experiences in the Philippines and in Ghana shows that the potential of LEISA to improve ecological and/or socio-economic sustainability depends on site-specific factors in the first place. In areas with a high production potential, LEISA can simultaneously improve ecological sustainability and farmers' socio-economic conditions by reduced use of external inputs. In areas with a low production potential, LEISA can stabilise and restore the carrying capacity, but generally has limited potential to improve socio-economic conditions for growing populations, and an increased production may also result from a further depletion of natural resources, and by a limited number of farmers. Other factors that can influence the potential and the applicability of LEISA are the production dip and the rehabilitation period involved, high labour requirements, land-ownership aspects, gender issues, constraints to implement a participatory technology development approach, macro-economic aspects, government influences and information dissemination. Together with the site-specific conditions, these aspects should be considered in planning and evaluation of LEISA techniques.
\end{abstract}

Keynords: low external input agriculture, sustainable agriculture, ecological agriculture, ecological sustainability, sustainable development

\section{Introduction}

Due to the necessity to feed growing populations and meet increasing market-oriented demands, current farming systems in the tropics tend to evolute into one of two extremes:

1. intensive use of external inputs (non-renewable resources; fertilisers, pesticides, fossil fuels), generally associated with cash-crop production, referred to as high external input agriculture (HEIA). HEIA farming systems are associated with the Green Revolution and are found mainly in ecologically 'high potential' areas in the tropics, and is most widespread in Asia. 


\section{J.J. KESSLER AND M. MOOLHUIJZEN}

2. intensive use of the locally available, renewable resources, with very few or no external inputs, generally for subsistence only, referred to as low external input agriculture (LEIA) or low-resource or resource-poor agriculture. About one quarter of the world's population depends on LEIA farming systems, mainly in ecologically 'low potential' areas; in terms of area it is most widespread in Sub-Saharan Africa (Reijntjes et al., 1992).

Both extremes can cause serious negative side-effects on the environment and on socio-economics of smallholder farmers. HEIA farming systems may lead to excessive use of agrochemicals with adverse effects on the environment (e.g. pollution, intoxication, loss of biodiversity), and on (parts of) the rural populations (dependency, effects on health, marginalisation and indebtedness, increased inequality) (Glaeser, 1987; Adams, 1990). LEIA farming systems may lead to over-exploitation of natural resources with adverse ecological effects (e.g. soil depletion, land degradation, loss of biodiversity) and on the rural populations (e.g. poverty and marginalisation).

Initially as a reaction on the disadvantages of the technocratic approach of the Green Revolution, alternative concepts of agricultural development were elaborated, commonly referred to as ecological, sustainable or low external input agriculture (Adams, 1990; Reijntjes et al., 1992). These concepts aim at adapting and designing the agricultural system to the environment, optimising the use of biological resources, including minimal changes in the natural ecosystem, and minimising the use of external inputs (Pimentel et al., 1989).

In 1987 the Brundtland commission defined the concept of Sustainable Development as: '..a process of change in which the exploitation of resources, the direction of investments, the orientation of technological development and institutional changes are in harmony and enhance both current and future potential to meet human needs and aspirations' (Brundtland, 1987). In analogy with sustainable development, sustainable agriculture may be defined as 'management of resources for agriculture to satisfy changing human needs, while maintaining or enhancing the quality of the environment and conserving the natural resources' (Reijntjes et al., 1992). Both concepts are accepted in current development cooperation (e.g. Anon., 1992a; 1992b; 1992 c) but their operationalisation appears to be difficult. Criteria are developed for specific situations and disciplines, but not so for complex systems and in an interdisciplinary context.

Financed by the Netherlands Directorate General of International Cooperation since 1983, the Information Centre for Low External Input and Sustainable Agriculture (ILEIA) aims at supporting farmers in tropical resource-poor environments, mainly by a supply and exchange of information on research results on and experiences with low external input agriculture. ILEIA introduced the LEISA acronym (Low External Input Sustainable Agriculture) as one concept of sustainable agriculture, that brings together environmental awareness and farmers' economic and social objectives by developing techniques that enhance optimal use of locally available resources. LEISA aims at improving farm household productivity, security (production variation), continuity (ecological sustainability) and identity (social justness and humaneness) (Reijntjes et al., 1992). 
LEISA techniques have rarely been analysed in a systematic way on their impact on sustainability of socio-economic conditions for farmers and ecological conditions (natural resources). Acknowledged limitations of LEISA techniques refer to their claimed ecological sustainability (e.g. for agroforestry: Kessler \& Breman, 1991), and to economic and political conditions limiting the potential of LEISA (e.g. Adams, 1990). From an initial overview of LEISA experiences, it appeared to the authors that success is often restricted to small areas with specific (favourable) conditions, and/or to a limited time period (Moolhuijzen and Kessler, 1993). It also appeared that organisations rarely explicitly formulate the results to be expected by adopting specific LEISA techniques, leading to variable and insufficiently specified objectives and results to be expected.

In view of the apparent lack of relevant evaluation data, the authors present in this article the results of a survey, executed in the framework of the evaluation of ILEIA. Although the survey did not aim at an in-depth systematic investigation of LEISA, from the analysis of fieldwork data interesting patterns appeared, which seem to be essential in order to understand relationships between success factors for LEISA and site conditions. The insights obtained and presented in this article contribute to the discussion whether LEISA claims of sustainability are justified, and if so for which LEISA techniques and under which conditions.

The abbreviations used in this article are summarised in Appendix 1.

\section{Materials and methods}

The following questions were formulated as starting points for the evaluation survey:

- how applicable/replicable are the LEISA techniques disseminated?

- are LEISA techniques as such ecologically sustainable?

- what are motivations to apply LEISA techniques, what are expectations?

- what are constraints for successful applications of LEISA techniques?

- is it possible to indicate systematic relations between success factors and site conditions, objectives, motivations and constraints for LEISA?

Field missions were executed in Ghana and the Philippines, because of (i) the presence of an ILEIA network and a local consultant, and (ii) sites in the two countries representing situations with highly variable economic and ecological conditions, allowing general conclusions in relation to the sustainability of LEISA techniques. The assessment concentrated on four clusters of LEISA techniques: maintenance of soil fertility, soil and water conservation, agroforestry and integrated pest management. In both countries institutions and programmes dealing with LEISA were visited, covering a wide range of site conditions and rate of success with LEISA techniques. In total $23 \mathrm{NGOs}$ were visited, $6 \mathrm{GOs}$ and 7 research institutions. In the field, 26 group discussions were held with farmers, on LEISA techniques and backgrounds. Group size varied from two to more than ten farmers; as much as possible women were encouraged to participate. The discussions took at least two hours, at most a whole day. 


\section{J.J. KESSLER AND M. MOOLHUIJZEN}

During the fieldwork, site conditions were evaluated according to:

* The ecological production potential, commonly referred to as the carrying capacity, which may be defined as 'the level of exploitation of renewable resources imposing limits on a specific type of land-use, that can be sustained without causing land degradation within a given area' (Kessler, 1994). ECO- refers to areas with a low carrying capacity, characterised by soil and/or climatic constraints for agriculture (poor soil fertility, mountainous areas, (semi-) arid climate mainly), generally leading to relatively low population densities (less than 100 inhabitants per $\mathrm{km}^{2}$ ). $\mathrm{ECO}+$ refers to areas with a high carrying capacity, characterised by suitable soil and climatic conditions (high soil fertility (e.g. volcanic or alluvial soils), nonmountainous, (sub-) humid climate mainly), generally leading to relatively high population densities (more than 100 inhabitants per $\mathrm{km}^{2}$ ).

* The relationship between the carrying capacity and the actual level of exploitation of renewable resources. Three phases can be distinguished (Figure 1): under-exploitation (phase 1), in transition/equilibrium (phase 2) and over-exploitation (phase 3). In phase 3 the land usually shows signs of degradation, and as a result it has a reduced carrying capacity (reduced production potential, decreasing yields). Degradation of ECO+ areas can lead to ECO-conditions.

* The economic conditions, such as infrastructure, purchasing power, density of and distance to markets, rate of industrialisation, off-farm employment opportunities, availability and prices of external inputs. ECONO- refers to (areas with) unfavourable economic conditions; ECONO+ refers to (areas with) favourable economic conditions.

In the Philippines, $\mathrm{ECO}+$ conditions prevail: rainfall is high everywhere, and soils are generally fertile (volcanic origin). Exceptions are mountainous areas, where soils are poor due to natural factors such as shallow or calcareous soil, rocky and sloping land. Degraded land (phase 3) occurs due to human factors, such as strong erosion following deforestation, depleted soils following too intensive cropping or unbalanced use of chemical fertilisers. ECONO+ conditions prevail, particularly where rice is grown, except for the inlands where infrastructure is poorly developed, inputs are not available, markets hardly developed etc.

In Ghana, fieldwork focused on the northern part of the country where ECO-conditions prevail: semi-arid climate and poor soils due to naturally low fertility and sandy texture. Here, phase 3 conditions are widespread, causing a further reduction of the carrying capacity. In southern Ghana ECO+ conditions occur in the inlands (sub-humid climate and fertile soils) except for the coastal region. ECONO-conditions prevail (poor infrastructure, low purchasing power, lack of inputs etc.), except for the coastal region and the vicinity of Accra.

\section{Results of the field surveys}

In this paragraph the main findings of the field mission are presented; where no specific country is mentioned the results apply to both the Philippines and Ghana. 


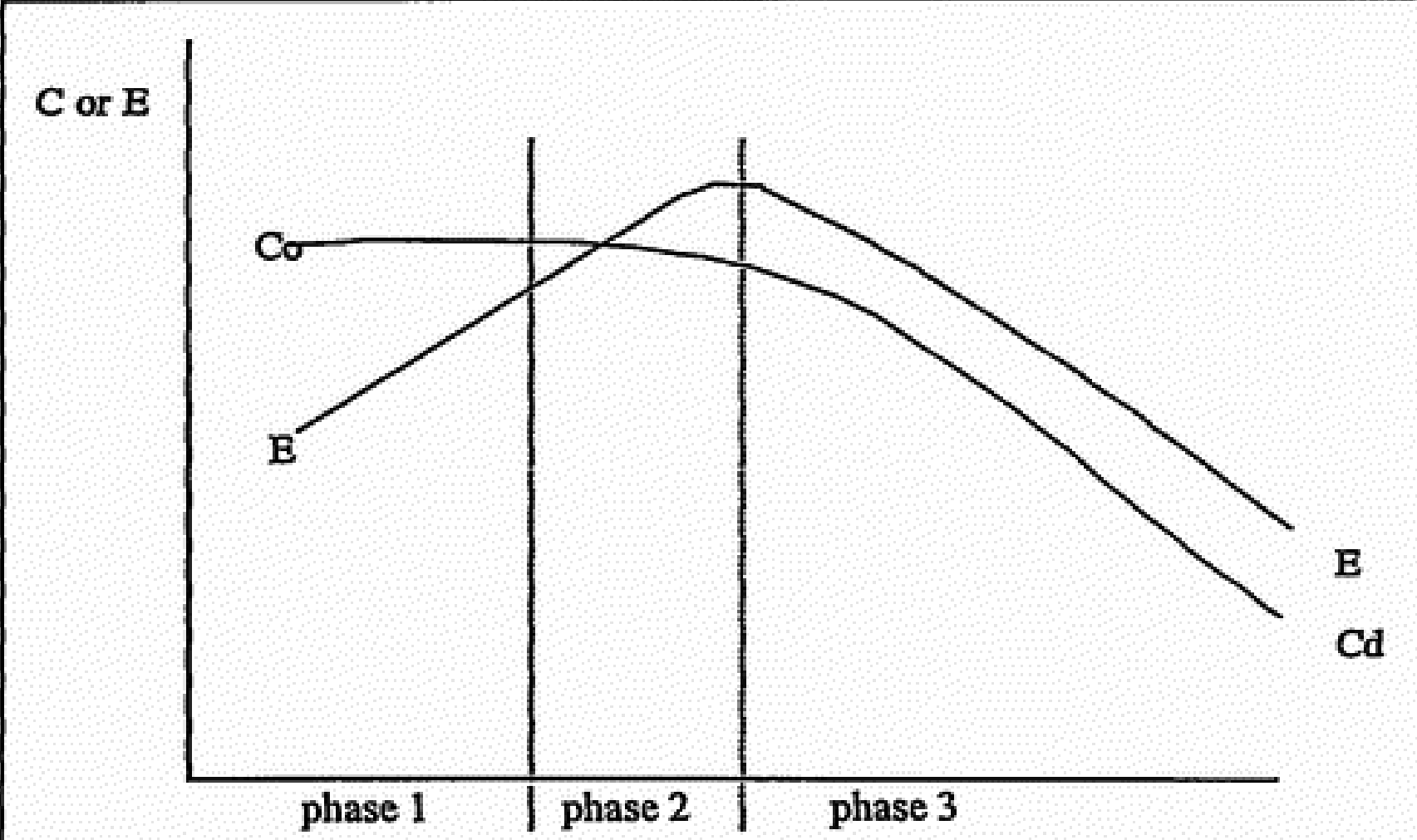

Figure 1. The relation between the exploitation level (E) and the carrying capacity (C) of renewable resources, in a phase of under-exploitation (1), transition/equilibrium (2) and over-exploitation (3). $\mathrm{C}_{0}$ is the carrying capacity of the intact agro-ecosystem, $C_{d}$ refers to a lower carrying capacity due to land degraded (Kessler, 1994).

\section{The LEISA concept in the field has many interpretations}

It was remarkable to find that the objectives and targets of LEISA applications are only vaguely specified and vary widely, and that the term LEISA is interpreted in various ways. Most people interviewed during the field mission associate LEISA with a limited use of external inputs, and a reduction in relation to present levels; several associate LEISA with farming systems that do not use any external inputs. Generally the implicit assumption is expressed that LEISA is beneficial for both the environment and the socio-economic position of the farmer.

\section{Different actors have different motivations to apply LEISA}

The motivation to apply LEISA techniques also varies widely; both between organisations and farmers, and amongst farmers. NGOs have most experience with LEIA farming systems and were among the first to adopt LEISA techniques, assuming that improving ecological conditions always contributes to poverty alleviation (i.e. improved socio-economic conditions). In the Philippines, NGOs consider LEISA as a movement 'against the main-stream', contributing to increased self-reliance, increased income equity and community organisation. Political motives have led to a dramatic increase in the number of NGOs in the Philippines, many of which adopt LEISA techniques. 


\section{J.J. KESSLER AND M. MOOLHUIJZEN}

Farmers adopt LEISA techniques mainly out of economic motives. Both in the Philippines and Ghana, NGOs complain that farmers ultimately discontinue the collaboration, no matter how friendly, if concrete results (economic benefits, increased crop production) do not show. Farmers in ECO - areas (e.g northern Ghana) have to deal with unpredictable ecological conditions determining agricultural production. As a result, concrete results in terms of increased income security are at least as important an objective as short-term productivity. In areas where the Green Revolution has had its impact (southern Ghana, the Philippines, generally ECO+ and ECONO+), the motivation to apply LEISA is increasing. This relates to the worldwide economic recession, which has led to reduced subsidies and an increase in the prices of external inputs (particularly in Ghana), a decrease in the benefits of several cash-crops (e.g. cotton), and reduced possibilities for off-farm employment in ECONO+ areas (employees even return to rural areas).

Among the motivations to apply LEISA, farmers also mentioned the services provided by NGOs, such as social welfare, community development, social empowerment, raising political consciousness and their intermediary role in land tenure conflicts. This so-called 'shadow participation' most clearly shows in Ghana. Health-related motivations are also important in HEIA farming systems; the most commonly mentioned are pesticides affecting human health.

Where renewable resources are readily available (Figure 1, phase 1), farmers appear little motivated to apply LEISA techniques, as it is less labour intensive to pursue a farming system that does not make the most efficient use of renewable resources (e.g. shifting cultivation in sparsely populated ECO+ areas in the Philippines). However, in phases 2 and 3 renewable resources become increasingly scarce, and farmers feel the need to increase labour inputs to develop more efficient farming techniques in order to maintain 'average' yields (provided that no off-farm alternatives are available). This was clearly observed in the degraded uplands in Cebu (Philippines) and in densely populated areas in southern Ghana.

Most donor agencies have recognised and accepted the value of LEISA and related concepts. The growing awareness of the ecological side-effects of agrochemicals (mainly in ECO+ areas) and the disappointing results of technological agricultural development programmes (mainly in ECO- areas), has led to a shift in attention to indigenous species and local land-use systems. GOs in both countries start adopting LEISA techniques, partly donor driven. Among GOs double standards are often encountered. For instance, in the Philippines, GOs support research and extension programmes on the use of organic fertilisers, but at the same time continue to subsidise chemical fertilisers. The political focus of LEISA is a threat for GOs in the Philippines.

\section{What are the constraints for LEISA?}

The survey highlights a number of general factors that influence the applicability of LEISA techniques, besides site-specific ones and those specific for the development agency. 


\section{(1) Production dip and rehabilitation period}

A period of decreased agricultural production follows the introduction of most LEISA techniques. For instance, when shifting from chemical to organic fertilisers, it takes several years to build up the organic matter content and fauna of the soil for organic inputs to become effective. Another example is alley cropping: the planted shrubs occupy a proportion of the agricultural land, whereas the shrubs and the alley cropping system become productive after several years only. In both HEIA and LEIA farming systems the survey showed that the production dip is perceived as a serious constraint.

The duration of the production dip (transition period) varies. In ECO+ areas it is of limited duration (3-5 years), as ecological processes are more rapid (recycling of nutrients, plant growth, nitrogen fixation etc.). In ECO- areas the period for full rehabilitation easily lasts more than ten years, since build up processes of biomass and organic matter are much slower (e.g. tree growth). Nevertheless, where phase 3 conditions prevail, soil and water conservation measures can have considerable shortterm benefits, due to the effective concentration on limited areas of resources that would otherwise have been lost by erosion. Restoration of production capacity of large areas will take much longer.

Due to unpredictable drought periods in semi-arid ECO- areas, returns of investments are less reliable than in most ECO+ areas. In northern Ghana, investing in land rehabilitation, using LEISA techniques, in most cases does not seem to be a rational option for farmers, although long-term benefits can be important. Transition strategies, including incentives and other support, seem to be indispensable to cover the production dip, but so far receive little attention.

\section{(2) Labour requirements}

Labour shortage can be a bottleneck in the application of LEISA techniques, most of which are very labour intensive, especially for small families, or those with migrant absentees (female-headed households). For some LEISA techniques labour requirements are much higher in ECO- areas, as compared to ECO+ areas (e.g. to collect organic material, since manure to be collected and fields to be fertilised are more widely dispersed). Farmers decisions to invest (extra) labour in LEISA techniques is influenced by the expected benefits in relation to and the availability of alternative sources of income. In ECO- areas (northern Ghana), poor farmers are not willing to increase labour inputs in LEISA where labour can be seasonally or permanently invested in less risky off-farm activities. Farmers appear willing to cover large distances to find such opportunities (e.g. migrants moving from northern Ghana to Accra). Even in $\mathrm{ECO}+$ areas, if profitable off-farm activities are available nearby (e.g. ECONO+ coastal areas in the Philippines), labour investments in LEISA techniques are not likely to be made. NGOs remark that high labour requirements of LEISA techniques conflict with social development activities such as children's and adult education and women's emancipation. Several labour saving tools are available (e.g. wheel barrows, animal traction), but in Ghana NGOs are often reluctant to provide such tools on credit because the income-generating effect for the farmers is too uncertain. 


\section{(3) Land-ownership}

The applicability of LEISA is higher where farmers own their land and have usufruct rights. It appears that tenant systems prevail in ECO+ and ECONO+ areas, where land has become scarce and valuable. Tenant farmers are discouraged or even prohibited to apply LEISA techniques that lead to land improvements, as is the case for smallholders in the highly productive lowlands of the Philippines, and in the coastal area of Ghana.

\section{(4) Gender}

Women appear more rapid in adopting all the LEISA techniques investigated. Nevertheless, both NGOs and GOs are still mainly staffed by men and orient their activities towards men. The constraints on LEISA, as for agricultural development in general, affect women more than men: women generally have less land ownership than men, labour constraints are more pressing, and women have less control over the profits of their labour investments in LEISA techniques. On the other hand, in Ghana some women's groups effectively plant trees and apply organic fertilisers on their common fields and manage their profits.

\section{(5) The Participatory Technology Development (PTD) approach}

An important instrument to develop LEISA techniques is the PTD approach, by which site-specific and socio-economically adapted techniques are developed and tested on-farm, based on farmers' indigenous knowledge, skills and priorities, with support from the capacities of external agents and agricultural science. During the field survey several observations were made of NGOs introducing LEISA techniques in a rather top-down way, aiming at quick results. Several constraints of the PTD approach were mentioned:

* although there is increasing awareness that, particularly in ECO- areas, knowledge of indigenous (traditional) farming systems is an essential basis of development options, it cannot be expected to provide permanent solutions to current farming systems constraints (the scale and character of the constraints being of a new order of magnitude);

* PTD is time consuming, both for extensionists and farmers, and it requires a relatively high level of training of the extensionist; NGOs commonly lack staff in sufficient numbers and of sufficient quality;

* on-farm demonstrations of LEISA techniques are rarely designed properiy, nor cover a sufficiently long period to draw firm conclusions;

* the potential of PTD to motivate farmers is strongly related to the possibilities of obtaining short-term (economic) benefits.

\section{(6) GO influences}

Both GO policies and officials in their private roles often pose constraints on the implementation of LEISA. GOs consider NGOs and LEISA techniques as undesirable since both may lead to increased farmers' self-reliance. Cases were encountered where GOs subsidise or provide favourable credit systems for external inputs only, organise (military) opposition to community organisation, corrupt LEISA enterpris- 
es, maintain unjust and unequal land tenure and usufruct policies, or support large traders frustrating small-scale farmers' enterprises. Particularly in the Philippines, GOs commonly oppose NGOs and LEISA adopting farmers' organisations until, sometimes, the success of a LEISA technique can no longer be denied.

\section{(7) Information dissemination}

The availability of technical information and examples of successful applications are important elements of the PTD approach to motivate farmers to adopt LEISA techniques. However, such information is often unavailable in areas where ECO- and ECONO- conditions prevail. On the other hand, in ECO+ areas in the Philippines the amount of information promoting the use of external inputs is overwhelming and difficult to counter by low-budget NGOs. Here, networking initiatives as developed by ILEIA have already led to important improvements of information disseminated among LEISA practitioners.

\section{Discussion}

\section{Relations between ecological and socio-economic conditions}

The LEISA concept suggests to be a strategy of sustainable agriculture, that simultaneously improves ecological sustainability and socio-economic conditions (sustainability) for poor farmers, and that is applicable to the tropics in general. LEISA is therefore embraced by both environmentalists and those oriented at alleviating rural poverty. The results of the survey show that it is questionable whether both objectives can always be met, depending on variation in site conditions in the first place.

HEIA farming systems are often encountered in areas characterised by both favourable ECO+ and ECONO+ conditions. Under such circumstances, there is a potential for certain LEISA techniques to meet the two objectives at the same time, because there is a relation between ecological problems and socio-economic problems of farmers. The unbalanced and excessive use of external inputs may lead to pollution and gradually decreasing yields (e.g. due to acidification and pest resistance), but also to loss of control over production means, decreasing incomes and increasing expenses (indebtedness) for smallholder farmers. Under such circumstances, a reduction in the use of external inputs improves both ecological and socio-economic conditions. The improved economy of the farmer is not so much because of improved yields (successful LEISA rice farmers in the Philippines even mentioned yield decreases), but because of reduced expenses and increased self-reliance. Here land tenure, political and macro-economic factors are major bottlenecks to successfully apply LEISA.

In LEIA farming systems, the techniques applied (traditionally or introduced) are less likely to meet both sustainability objectives at the same time. In other words, it is doubtful whether the techniques are correctly referred to as LEISA. Here, ecological and socio-economic problems for farmers are related in a different way. Ecological potential is low (ECO-), or has become low due to land degradation 
(Figure 1; phase 3), and farmers use little or no external inputs (so heavily depend on scarce renewable resources) mainly because of predominating ECONO-conditions. Because of the combination of scarce natural resources and unfavourable economic conditions there is less potential to improve the economic conditions of farmers, either by reducing financial costs (which are non-existent) or by improving agricultural production without the use of external inputs. The latter is related to the question how and where LEISA techniques can actually be ecologically sustainable.

\section{The ecological sustainability of LEISA}

LEISA is promoted as a sustainable alternative for agricultural development of LEIA farming systems where the use of external inputs is not (anymore) feasible and is as such part of Dutch development policy (Anon., 1992a; 1992b). However, the assumption that all LEISA techniques are always ecologically sustainable, in ECOareas in particular, continues to be subject of debate. It is argued that short-term production increases resulting from the application of certain LEISA techniques (thus improving economic conditions) are often at the expense of ecological sustainability. It is essential to discuss some ecological principles in order to understand this apparent controversy.

Renewable resources required for crop production are nutrients, water and light. Agricultural intensification, defined as the increase of yields (i.e. production per unit of area), is indispensable for agricultural development with growing populations (Breman, 1992). Higher agricultural production levels achieved without the (increased) use of external inputs (i.e. by LEISA techniques), are invariably related to higher exploitation rates of renewable resources. Whether these rates are sustainable depends on the potential to realise the production increase by any or a combination of the four following principles: spatial concentration, enrichment, increased efficiency and reduction of losses of natural resources (Reijntjes et al., 1992).

Resource losses due to erosion and leaching can be reduced by maintenance of a vegetation cover and of a dense and perennial root system, and soil and water conservation constructions. Enrichment processes may take place by the uptake of nutrients from deep soil layers by deep-rooting trees, or by nitrogen fixation by leguminous plants. The potential for the reduction of losses or an enrichment of the ecosystem is highest in ECO+ areas, where leaching losses can be reduced, and where the potential for nitrogen fixation is high. In $\mathrm{ECO}$ - areas the increase of agricultural production by LEISA techniques usually results from a net nutrient flow to the croplands due to the effective spatial concentration of resources, e.g. collection and deposition on croplands of manure, crop residues, cut grasses or tree leaves. In resource-poor environments these measures risk depletion and over-exploitation of renewable resources in the area of their origin (mainly rangeland areas), contributing to further marginalisation of pastoralists and over-exploitation of rangelands. For instance, in ECO- areas agroforestry has little potential to increase crop production; the role of woody plants is mainly one of stabilising soil dynamics and of production diversification (Kessler \& Breman, 1991).

The short-term benefits from many soil and water conservation measures (IFAD, 
1992) are partly based on the above 'concentration' principle. Improved production levels following soil and water conservation are obtained on small areas, and largely depend on other sub-systems (e.g. degraded uplands) providing the inputs of water, nutrients and organic matter that accumulate in front of the anti-erosion structures or in planting holes (Figure 2). This is particularly the case in ECO-areas where plant growth and soil formation are slow. In general, land rehabilitation aimed at restoring the production capacity of the land requires build up of biomass and organic matter in and on the soil. Hence, exploitation levels should be kept low.

There is increasing evidence that in ECO- areas, where exploitation levels of renewable resources are relatively high (Figure I: phase 2 or 3 ), the efficiency of the use of renewable resources by indigenous techniques is already quite high, simply because subsistence farmers have no alternatives (Breman, 1992). The results of the field survey support the growing awareness that in ECO- areas this efficiency cannot be much improved by introducing other LEISA techniques or by improving traditional techniques, without additional external inputs. Where production increases are obtained, there is a serious risk of increasing (over-) exploitation of scarce renewable resources. Spatial concentration processes are often at the basis of improved crop production. For instance, a common LEISA technique is to improve crop pro-

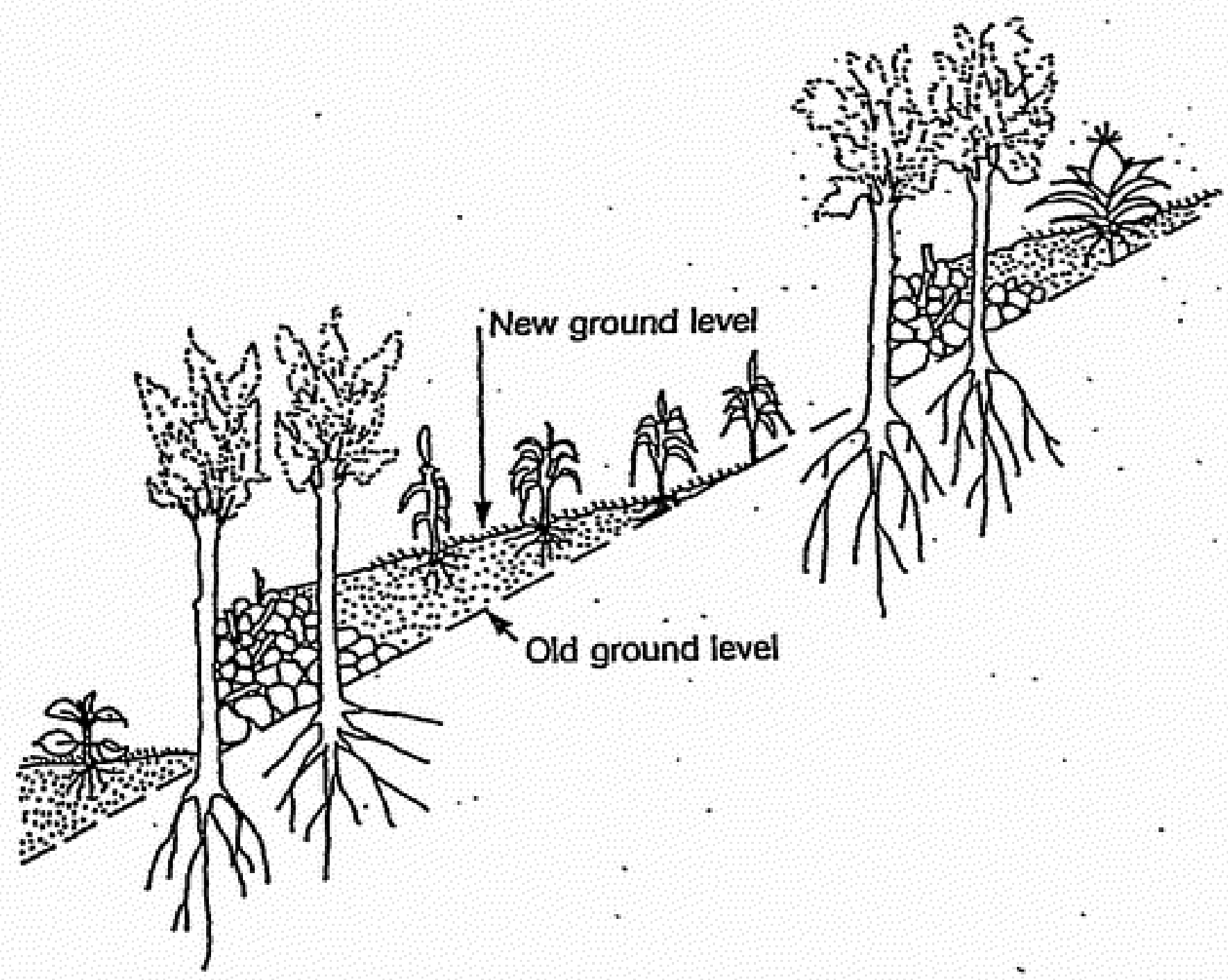

Figure 2. Terraces constructed by capturing soil inputs that originate from upslope erosion. 


\section{J.J. KESSLER AND M. MOOLHUIJZEN}

duction by manure pits or compost heaps, which requires large quantities of biomass and manure. NGOs therefore often uncritically promote keeping livestock, without considering risks of over-grazing, and competition with pastoralists.

It appears that for LEIA farming systems in ECO- areas a choice has to be made between either activities aimed at short-term improvement of the economic conditions of farmers by increased resource exploitation (thus reducing ecological sustainability), or measures aimed at maintenance of the ecological production potential, accompanied by transition strategies to overcome the disadvantageous (socioeconomic) consequences for farmers. In northern Ghana and in degraded ECONOareas in the Philippines, LEISA techniques generally are feasible only if funding agencies substantially support the actors involved during a transition phase. After this phase, further intensification of agricultural production with an optimal balance of natural and external inputs will contribute to meet socio-economic objectives.

Most farmers of LEIA farming systems interviewed during the survey, were eager to use external inputs as soon as their availability would be improved and/or costs reduced, realising that their present situation is not sustainable. The use of external inputs, also in resource-poor environments, is indispensable for sustainable land use with growing populations (van Keulen \& Breman, 1990).

\section{Conclusions}

The survey had an exploratory character mainly, and therefore did not follow an experimental design. Nevertheless, from the limited data set obtained, interesting patterns appear as regards the potential of LEISA techniques to improve socio-economic sustainability for the farmer (by reduced costs and/or increased production mainly) in such a way that ecological sustainability is maintained. In ECO+ areas, for several LEISA techniques this potential is high. Here, the major constraints for sustainable agriculture are factors that are usually beyond the influence of agencies implementing LEISA, such as land tenure, price policies and macro-economic factors. In ECO- areas, for most LEISA techniques this potential is limited. Here, LEISA techniques should be implemented with care because:

* production increase often results from an effective spatial concentration and exploitation of scarce resources;

* production increase often results from an increased utilisation of scarce resources by few successful farmers, thus reducing access to such resources for other farmers, or for pastoralists;

* land rehabilitation can be very effective, but investments are high;

* benefits from labour inputs to implement LEISA are often less than those obtained by off-farm employment.

As regards the relationship between economic conditions and the potential of LEISA techniques, ECONO+ conditions may be beneficial (e.g. more organic wastes available, good infrastructure, social services, demand for ECO-products), but can also be disadvantageous by providing better opportunities for off-farm employment and by more effective Green Revolution like campaigns. 
Farmer's motivations to apply LEISA techniques are related to the potential for short-term improvements of socio-economic conditions, and vary according to the prevailing phase indicated in Figure 1. Motivation is low when renewable resources are still plenty available (phase 1), but increases as renewable resources become scarce (phases 2 and 3), and as alternative sources of income are not available.

We recommend that the selection of LEISA techniques, the conditions of application, and the results to be expected, are better adapted to prevailing ecological and economic conditions, and according to HEIA and LEIA farming systems. More systematic data should be collected on farmers successfully and unsuccessfully implementing LEISA techniques, particularly regarding the constraints mentioned in this article. For donors, key issues to consider are credit systems and transition strategies to cover production dips, and inconsistencies in policies and strategies, particularly as regards subsidy and credit policies, and regulations on land tenure and natural resource management. Institutes should investigate LEISA techniques at a regional scale that includes all ecological and economic interactions influencing the farming system.

\section{Acknowledgements}

The evaluation took place at the demand of, and financed by the Environmental Spearhead Programme of the Netherlands Directorate General of International Cooperation (DGIS/DST/ML). We particularly acknowledge Henri Jorritsma from DGIS/DST/ML, Bertus Haverkort and Coen Reijntjes from the ILEIA team, and reviewers from this journal, for their cooperation and useful comments.

\section{References}

Adams, W.M., 1990. Green development, environment and sustainability in the third world. Routledge, London, $257 \mathrm{pp}$.

Anonymous, 1992a. A World of Difference. (In Dutch). Directorate General of International Cooperation (Foreign Aid), Ministry of Foreign Affairs, the Hague, 285 pp.

Anonymous, 1992b. Sustainable land-use. (In Dutch). Sector- en thema beleidsdocumenten van Ontwikkelingssamenwerking 2. Directorate General of International Cooperation (Foreign Aid), Ministry of Foreign Affairs, the Hague, $68 \mathrm{pp}$.

Anonymous, $1992 \mathrm{c}$. Sustainable development and the environment. FAO Policies and Actions. Food and Agriculture Organisation, Rome, 88 pp.

Breman, $H_{n}$ 1992. Agro-ecological zones in the Sahel: potentials and constraints. In: Poverty and Development. 4. Sustainable development in semi-arid sub-saharan Africa. Royal Tropical Institute, Amsterdam, pp. 19-36.

Brundtland, G.H., 1987. Our Common Future. World Commission on Environment and Development. Oxford University Press, Oxford, 383 pp.

Glaeser, B. (ed.). 1987. The Green Revolution Revisited: critique and alternatives. Allen and Unwin, Hamstead, UK, 206 pp.

IFAD, 1992. Soil and water conservation in Sub-Saharan Africa. A report prepared for the International Fund for Agricultural Development by the Centre for Development Cooperation Services, Free University, Amsterdam, 110 pp. 


\section{J.J. KESSLER AND M. MOOLHUIJZEN}

Kessler, J.J. 1994. The usefulness of the human carrying capacity concept in assessing sustainability of agricultural land-use in semi-arid regions. Agriculture, Ecosystems and Environment 48: 273-284.

Kessler, J.J. \& H. Breman. 1991. The potential of agroforestry to increase primary production in the Sahelian and Sudanian zones in West Africa. Agroforestry Systems 13: 41-62.

Keulen, H. van \& H. Breman. 1990. Agricultural development in the West African Sahelian region: a cure against land hunger? Agriculture, Ecosystems and Environment 32: 177-197.

Moolhuijzen, M.\& J.J. Kessler. I993. A closer look at LEISA techniques, a contribution to the pre-evaluation of the ILEIA project, phase III. Matrix Consultants, Utrecht, The Netherlands, 95 pp.

Pimentel, D., T.W. Culliney, I.W. Buttler, D.J. Reinemann \& K.B. Beckman. 1989. Ecological resource management for a productive, sustainable agriculture. In: D. Pimentel and C.W. Hall (Eds.), Food and Natural resources. Acad. Press Inc., New York, pp. 301-334.

Reijntjes, C., B. Haverkort \& A. Waters-Bayer. 1992. Farming for the future. An introduction to lowexternal-input sustainable agriculture. MacMillan Press, London, $250 \mathrm{pp}$.

\section{Appendix 1. Abbreviations used.}

$\begin{array}{ll}\text { ECO-/+: } & \text { Ecological potential low/high } \\ \text { ECONO-/+: } & \text { Economical potential low/high } \\ \text { GO: } & \text { Governmental Organisation } \\ \text { HEIA: } & \text { High External Input Agriculture (farming system) } \\ \text { ILEIA: } & \begin{array}{l}\text { Information Centre for Low External Input and Sustainable } \\ \text { Agriculture }\end{array} \\ \text { LEIA: } & \begin{array}{l}\text { Low External Input Agriculture (farming system) } \\ \text { LEISA: }\end{array} \\ \text { NGO: } & \text { Low External Input Sustainable Agriculture } \\ \text { PTD: } & \text { Non Governmental Organisation } \\ & \text { Participatory Technology Development }\end{array}$

